Professor Marius MARINAS, PhD

E-mail: marius.marinas@economie.ase.ro

Professor Marin DINU, PhD

E-mail: marin.dinu@economie.ase.ro

Professor Aura Gabriela SOCOL, PhD

E-mail: aura.socol@economie.ase.ro

Professor Cristian SOCOL, PhD

E-mail: cristian.socol@economie.ase.ro

Department of Economics and Economic Policies

The Bucharest University of Economic Studies

\title{
THE TECHNOLOGICAL TRANSITION OF EUROPEAN MANUFACTURING COMPANIES TO INDUSTRY 4.0. IS THE HUMAN RESOURCE READY FOR ADVANCED DIGITAL TECHNOLOGIES? THE CASE OF ROMANIA
}

\begin{abstract}
Expansion of digitalization creates the opportunity to transform production technologies and enables technological integration of the supply chain, according to the fourth industrial revolution (Industry 4.0). These technologies aim at creating smart manufacturing, where the production system is capable of automatically reconfiguring itself, based on the integration of hardware, software, and connectivity technologies. The technological transition process is influenced not only by certain digital prerequisites, but also by the ability of the human resource to acquire new digital skills. The study aims to estimate patterns both for the adoption of new technologies in European manufacturing companies, and for the human resource readiness for new technological challenges. Following the principal component analysis method, we estimated a further widening of development gaps between leading and laggard countries (including Romania) in technology. The less developed countries have the chance to skip certain stages of the transition towards Industry 4.0, as a result of promoting smart policies to harness their potential for digitalization.
\end{abstract}

Keywords: advanced digital technologies, digital skills, stage skipping, technological gap.

JEL Classification: D80, J24, O33, 038

\section{Introduction}

The fourth industrial revolution (Industry 4.0) integrates interoperable software, hardware, and connectivity technologies to automatically control the

DOI: 10.24818/18423264/55.2.21.02 
value chain components within a company (UNIDO, 2019a). In a smart factory, smart sensors are embedded into hardware equipment (robotics and 3D printing), through which big data is collected. The data is sent via the industrial Internet of things (IIoT) to the smart software, which analyzes, stores, and processes them automatically, allowing machines and humans to anticipate obstacles and to make the best decisions in real time, like in a network-type cyber-physical system. IIoT is a concept similar to the Internet of things (IoT), which entails connections between industrial equipment, data, and workers.

The progress of digitalization is heterogeneous across European Union (EU) countries, due to the development and technological gaps of CEE and Southern European (SE) countries, relative to the European average. Thus, the four most digitalized EU countries are Finland, Sweden, the Netherlands, and Denmark, which are also among the worldwide innovation leaders. Romania is, alongside Bulgaria, a modest innovator, according to the European Innovation Scoreboard 2020, whereas the innovation leaders are Denmark, Finland, Luxembourg, the Netherlands, and Sweden, which have the largest R\&D expenditure and apply most manufacturing innovation patents. There can be two possible effects of the new technologies on the development gaps. On the one hand, developed countries, which were also the Industry 3.0 leaders, will make a faster transition towards smart manufacturing, and the gaps between them and less developed countries will widen. On the other hand, laggard countries have the chance to skip stages and make quick progress towards the new industrial revolution, which will allow them to narrow the technological gap. The possibility does exist, but in the absence of prerequisites related to automation, digitalization, or digital skills, the convergence with developed countries will not occur.

There are two worldwide strategies for the implementation of advanced digital technologies in the manufacturing sector. The most common strategy is the gradual use of new digital technologies in existing companies, which corresponds best to the technological transition process. It involves, inter alia, an integrated value chain, a digitalization of routine tasks, or investment in software solutions and advanced technological equipment (Andreoni and Anzolin, 2019). The second strategy is a "technological boom" that refers to the implementation of smart manufacturing technologies in new manufacturing plants. It is the best example of skipping stages in the transition process towards Industry 4.0.

Within this study, we set myself to analyze the ability of European manufacturing companies to implement new technologies, taking into account both technological gaps and skill shortages. This study is original because it estimates the patterns for the implementation of the most advanced digital technologies in the European manufacturing sector, whereas other studies usually focus on only one or a few of those technologies. Moreover, it is the first study that assesses the readiness of Romanian companies and human resources for Industry 4.0.

The study is structured in three parts. The first aims to analyze the specialized literature on Industry 4.0, the advanced digital production technologies,

DOI: $10.24818 / 18423264 / 55.2 .21 .02$ 
The Technological Transition of European Manufacturing Companies to Industry 4.0. Is the Human Resource Ready for Advanced Digital Technologies? The Case of Romania

and the digital skills of the workforce. In the second one, we used the Principal component analysis method to estimate the patterns of adjustment of European manufacturing companies and of human resources to the new advanced digital production technologies (ADP technologies). Although the results suggest widening technological gaps between European countries, we proposed several recommendations meant to ensure a faster transition to smart manufacturing and leaps in technology development.

\section{Literature review}

Within this section, we explain the main characteristics of Industry 4.0 according to the literature review to understand both the key technologies of smart manufacturing and the technological challenges that companies face today. The Industry 4.0 concept has almost 100 definitions (Gulot et al., 2020) and it refers to a new manufacturing transformation stage through digitalization. Within Industry 4.0 , the production system is different from that of previous industrial revolutions, because it is based on interconnected and interoperable systems, and on advanced digital technologies that automatically adjust production processes (Thames and Schaefer, 2017).

By implementing the technologies of Industry 4.0, European manufacturing companies will create more intelligent products based on cyberphysical systems, where the physical and virtual space will be integrated with the help of the Internet of Things (Greer et al., 2019). Transition to Industry 4.0 involves structural changes in business models towards digitalization, generating higher productivity and competitiveness in the manufacturing sector, especially for companies that are able to react to technological challenges (Luthra and Mangla, 2018). Technological transformation will cover all value chain components, the aim being their full integration to ensure an interconnected system between workers, production equipment, and products (Naude, 2017). Following this process, companies will be able to collect and process a large amount of data in real time, which is used by the entire flexible production system with the help of other digital technologies (Boston Consulting Group, 2019). Bajenaru et al. (2016) proposed a new mechanism - ontology-based e-learning system - for implementation in the management of human resources and other platforms used by smart companies. Integrating new technologies into manufacturing processes will create smart manufacturing. Smeureanu and Bassel (2020) showed that there is a strong influence of high-tech factors on the proper functioning of companies during the coronavirus crisis.

Smart manufacturing is a new version of intelligent manufacturing based on artificial intelligence and on other digital production technologies. According to the authors (Zheng et al., 2018), smart manufacturing includes communication

DOI: 10.24818/18423264/55.2.21.02 
technologies, sensors, and information collected from different stages of production. To analyze the transition of the manufacturing sector to Industry 4.0, we considered the advanced digital production technologies that are enablers of transforming the entire value chain and the business model. The report (UNIDO, 2020) analyzed the new technologies from the perspective of an integrated and flexible system consisting of hardware (advanced robots, 3d printing), software (artificial intelligence, cloud computing, big data), and connectivity (Industrial Internet of Things - IIoT). In our opinion, researchers (Leitao et al., 2020) conducted the best analysis of the most cited key technologies in the Industry 4.0 literature, concluding that the Internet of Things, artificial intelligence, and big data are the most important in the digital transformation process.

Besides the physical and virtual resources needed for the transition to Industry 4.0, workers in manufacturing companies should have digital skills specific to the new advanced production technologies. A larger change in the demand for the skills of human resources represents one of the three main effects of Industry 4.0, along with the integrated production system and the disruption of the current value chains and business models (Glawe and Wagner, 2020). Digitalization of business processes requires upskilling of training for workers (Calza and Fokeer, 2019). Consequently, companies should implement an integrated skills development strategy that enables workers to interact with the machines both in the real and virtual space, to analyze various problems, to solve them, and to make decisions. The education, as well as the professional training system must keep up with the technological progresses to ensure ICT and STEM skills are above the basic level (Morandini et al., 2020), which are complementary to soft skills, such as cognitive or socio-emotional ones.

\section{Methodology}

In this study, we used the principal components analysis (PCA) method to analyze the transition process of the European manufacturing sector to Industry 4.0 digital technologies and to assess the readiness of human resources for new technical and digital skills. The selection of PCA method has been influenced by its ability to estimate patterns emerging from a multitude of technologies and skill data. In the beginning, we opted for the factors that show a certain correlation, and then we estimated the principal components, which represent linear combinations between the original variables and reflect certain patterns for the studied topic.

The principal component analysis method transforms $N$ explanatory variables between which there is a statistically significant correlation, into $N$ new variables between which there is no correlation. The method is used to econometrically estimate the common patterns in the original data, transforming them into a smaller number of principal components. Bartlett and Kaiser-MayerOlkin tests are used to identify the correlations and patterns for principal components. Thus, the Bartlett test uses the chi-square test, which corresponds to a normal distribution for a large number of variables, whereas the KMO test is based

DOI: 10.24818/18423264/55.2.21.02 
The Technological Transition of European Manufacturing Companies to Industry 4.0. Is the Human Resource Ready for Advanced Digital Technologies? The Case of Romania

both on the correlation matrix and on the partial covariance matrix between the original variables (Yong and Pearce, 2013). Since the Bartlett test rejects the null hypothesis of an "identity matrix", then it can be supposed that there are no such strong correlations between variables that would suggest the presence of multicollinearity. Instead, the KMO test suggests that the correlations between variables are not weak, as this would have meant that the original variables were not relevant to capture a particular pattern.

The main result of applying PCA method consists in the estimation of the correlation matrix between the original variables and of coefficients or weights (factor loading) that capture the relevance of the original variables in the principal components estimated. In the specialized literature, it is considered that a factor loading value greater than 0.5 ensures a good statistical significance of the principal components considered (Hair, 2019). The number of the principal components will be equal to that of the original variables, the relevance of each being considered according to the ability to explain a large proportion of the sample variance. Once the methodology has been agreed, we applied it to estimate the pattern of the manufacturing companies' transition to advanced digital production technologies (ADP technologies model) and a pattern of human resource readiness for new advanced digital technologies (Skills and specializations model).

\section{Results}

\subsection{Advanced digital production technologies (ADP technologies model)}

To carry out a comprehensive analysis of the technological transition to Industry 4.0, we used advanced digital technologies specific to all components of an integrated production system, according to (UNIDO, 2019a), except for AI technology, which is not reported separately for the manufacturing companies. However, big data analysis, advanced robots, or IIoT connectivity already incorporate artificial intelligence. The source of data is the Eurostat database, which selected the outcomes of the annual survey conducted by the European Commission on ICT Usage and e-commerce in Enterprises (Eurostat, 2020).

The 11 variables used in the first model are expressed as a percentage of companies that use a particular technology, indicating the degree of diffusion of advanced technologies in manufacturing companies in the last year with available data (2017, 2018 or 2019, according to Eurostat). The adoption of advanced digital production technologies in European manufacturing companies is not possible without certain digital prerequisites, such as fast internet, broadband connection, online sales, or social platforms, according to Digital Intensity Index (E_HDI). In terms of advanced software, we used variables related to big data analysis, cloud computing services, and software solutions for integrated production systems. Adopting big data analysis (E_BD) implies using various technologies (including machine learning) to extract from internal and external sources a large amount of

DOI: 10.24818/18423264/55.2.21.02 
information, which is processed and used in real time within all value chain segments.

We used two variables for cloud computing services accessed by companies via the Internet. The first one (E_CC) refers to the application of this technology for storage capacity, computing power, or for various software, whereas the second one is much better adapted to Industry 4.0 characteristics - high cloud computing services (E_CC_HI). The ERP (enterprise resource planning) system is an essential part of the Cyber-Physical System, allowing the integration of all production-specific operations into a homogeneous system. Through a software package, ERP system is connected to all devices and hardware-software systems of a company, facilitating the flow of information between them and workers to make business decisions (E_ERP). One of the ERP components is customer relationship management $(\mathrm{CRM})$, which allows targeting products according to the consumer preference changes (E_CRMAN).

From the perspective of hardware equipment, we included variables related to the use of 3D printing and industrial robots. 3D printing technology involves reprogramming and automatic control through software, to create prototypes, models or to produce a certain good. The first variable (E_P3D) refers to the use of this technology from various sources, regardless of the purpose, whereas the second one (E_P3D_PGPP) targets the production of goods in the manufacturing sector. The difference between industrial robots (E_RBTI) and 3D printing is given by the multipurpose character, which allows robots to adapt according to several operations to be executed.

One of the most widely used IIoT technologies for extracting information is the use of sensors or RFID tags embedded into certain equipment, which transmit information via radio waves to allow them to connect. By using RFID technology, every object and production equipment in a company will be able to connect to the network, allowing it to collect, send, and receive data, which corresponds to Industrial Internet of Things. To capture the particularities of the RFID technology, we considered two variables. The first one (E_RFID) refers to using this technology in a general sense, whereas the second one (E_RFPSDP) captures the particular case of using it as part of the production process.

We kept in the analysis only European countries (21 from 27) for which all data were available. The cleavage between Northern Europe and the CEE countries, due to the technological gap between them, is specific for the majority of the original variables. As a rule, the technologies with lower spread in European manufacturing companies, such as 3D printing for the production of goods and the use of RFID as part of the production process, have a very low dispersion (about $2 \%$ ) between countries. Romania is a special case in the EU regarding the spread of advanced technologies in the manufacturing sector. As a large part of the Romanian manufacturing sector uses technologies from previous stages of development, then companies have limited access to new technologies. 
The Technological Transition of European Manufacturing Companies to Industry 4.0. Is the Human Resource Ready for Advanced Digital Technologies? The Case of Romania

According to the PCA method, we proceeded to calculate the bilateral correlations of the original variables used in the ADP technologies model, the results being included in Table 1 . Thus, digital intensity has a statistical significant correlation with most other variables, showing that the digitization prerequisites favor the adoption of new technologies. Big data has a correlation of 0.51 with ERP, meaning that the integration of processes involves increasing the volume of data shared within a company, which must be analyzed and processed. A correlation of 0.81 between cloud services and the use of industrial robots suggests the possibility of adopting cloud robotics technology, which allows the use of additional resources from the cloud to increase computational power, learning capacity and interconnection of industrial robots. Another high correlation (0.78) was observed for the two hardware components (industrial robots and 3D printing). IIoT has the lowest correlations with other variables, as there is currently a weak complementarity with big data and cloud computing services technologies. E_RFPSDP variable is not correlated with the others (except for E_RFID), suggesting that European manufacturing companies still have difficulties in managing the connection of machines and devices to control the production flow.

Table 1. Correlation (ADP technologies model)

\begin{tabular}{|c|c|c|c|c|c|c|c|c|c|c|c|}
\hline Variables & $\begin{array}{c}\text { E_H } \\
\text { DI }\end{array}$ & $\begin{array}{c}\text { E_B } \\
\text { D }\end{array}$ & $\begin{array}{c}\text { E_C } \\
\text { C }\end{array}$ & $\begin{array}{c}\text { E_CC } \\
\text { _HI }\end{array}$ & $\begin{array}{c}\text { E_E } \\
\text { RP }\end{array}$ & $\begin{array}{c}\text { E_C } \\
\text { RM } \\
\text { AN }\end{array}$ & $\begin{array}{c}\text { E_P } \\
\text { 3D }\end{array}$ & $\begin{array}{c}\text { E_P } \\
\text { 3D_F } \\
\text { PGP } \\
\text { P }\end{array}$ & $\begin{array}{c}\text { E_R } \\
\text { BTI }\end{array}$ & $\begin{array}{c}\text { E_R } \\
\text { FID }\end{array}$ & $\begin{array}{c}\text { E_R } \\
\text { FPS } \\
\text { DP }\end{array}$ \\
\hline E_HDI & $\mathbf{1}$ & $\mathbf{0 . 4 8}$ & $\mathbf{0 . 9 4}$ & $\mathbf{0 . 9 1}$ & $\mathbf{0 . 6 6}$ & $\mathbf{0 . 5 5}$ & $\mathbf{0 . 7 5}$ & $\mathbf{0 . 5 8}$ & $\mathbf{0 . 8 1}$ & 0.35 & 0.15 \\
\hline E_BD & $\mathbf{0 . 4 8}$ & $\mathbf{1}$ & 0.43 & 0.41 & $\mathbf{0 . 5 1}$ & $\mathbf{0 . 4 4}$ & $\mathbf{0 . 5 5}$ & $\mathbf{0 . 5 0}$ & 0.37 & 0.39 & 0.14 \\
\hline E_CC & $\mathbf{0 . 9 4}$ & 0.43 & $\mathbf{1}$ & $\mathbf{0 . 9 7}$ & $\mathbf{0 . 5 9}$ & $\mathbf{0 . 4 8}$ & $\mathbf{0 . 6 6}$ & $\mathbf{0 . 5 3}$ & $\mathbf{0 . 8 1}$ & 0.27 & 0.23 \\
\hline E_CC_H & & & & & & & & & & & - \\
I & $\mathbf{0 . 9 1}$ & 0.41 & $\mathbf{0 . 9 7}$ & $\mathbf{1}$ & $\mathbf{0 . 5 1}$ & 0.43 & $\mathbf{0 . 5 3}$ & 0.39 & $\mathbf{0 . 7 4}$ & 0.25 & 0.24 \\
\hline E_ERP & $\mathbf{0 . 6 6}$ & $\mathbf{0 . 5 1}$ & $\mathbf{0 . 5 9}$ & $\mathbf{0 . 5 1}$ & $\mathbf{1}$ & $\mathbf{0 . 7 9}$ & $\mathbf{0 . 8 4}$ & $\mathbf{0 . 6 0}$ & $\mathbf{0 . 8 1}$ & $\mathbf{0 . 5 3}$ & 0.12 \\
\hline $\begin{array}{c}\text { E_CRM } \\
\text { AN }\end{array}$ & $\mathbf{0 . 5 5}$ & $\mathbf{0 . 4 4}$ & $\mathbf{0 . 4 8}$ & 0.43 & $\mathbf{0 . 7 9}$ & $\mathbf{1}$ & $\mathbf{0 . 6 5}$ & $\mathbf{0 . 4 9}$ & $\mathbf{0 . 5 9}$ & $\mathbf{0 . 5 3}$ & 0.11 \\
\hline E_P3D & $\mathbf{0 . 7 5}$ & $\mathbf{0 . 5 5}$ & $\mathbf{0 . 6 6}$ & $\mathbf{0 . 5 3}$ & $\mathbf{0 . 8 4}$ & $\mathbf{0 . 6 5}$ & $\mathbf{1}$ & $\mathbf{0 . 9 0}$ & $\mathbf{0 . 7 8}$ & $\mathbf{0 . 5 1}$ & 0.02 \\
\hline $\begin{array}{c}\text { E_P3D_P } \\
\text { GPP }\end{array}$ & $\mathbf{0 . 5 8}$ & $\mathbf{0 . 5 0}$ & $\mathbf{0 . 5 3}$ & 0.39 & $\mathbf{0 . 6 0}$ & $\mathbf{0 . 4 9}$ & $\mathbf{0 . 9 0}$ & $\mathbf{1}$ & $\mathbf{0 . 5 7}$ & 0.39 & 0.05 \\
\hline E_RBTI & $\mathbf{0 . 8 1}$ & 0.37 & $\mathbf{0 . 8 1}$ & $\mathbf{0 . 7 4}$ & $\mathbf{0 . 8 1}$ & $\mathbf{0 . 5 9}$ & $\mathbf{0 . 7 8}$ & $\mathbf{0 . 5 7}$ & $\mathbf{1}$ & 0.41 & 0.04 \\
\hline E_RFID & 0.35 & 0.39 & 0.27 & 0.25 & $\mathbf{0 . 5 3}$ & $\mathbf{0 . 5 3}$ & $\mathbf{0 . 5 1}$ & 0.39 & 0.41 & $\mathbf{1}$ & $\mathbf{0 . 6 3}$ \\
\hline $\begin{array}{c}\text { E_RFPS } \\
\text { DP }\end{array}$ & -0.15 & 0.14 & 0.23 & -0.24 & 0.12 & 0.11 & 0.02 & 0.05 & 0.04 & $\mathbf{0 . 6 3}$ & $\mathbf{1}$ \\
\hline
\end{tabular}

Values in bold are different from 0 with a significance level alpha $=0.05$

DOI: 10.24818/18423264/55.2.21.02 
The application of the PCA method in the ADP technologies model meets the relevant statistical criteria. Thus, the Kaiser-Mayer-Olkin test has a value of 0.74 , higher than the threshold of 0.5-0.7 according to the literature, which signals the presence of common factors. In addition, the Bartlett Test rejects the null hypothesis of "identity matrix", the observed value of a chi-square being 233.35, compared to a critical value of 73.31. We used XL-STAT software and noticed that only two principal components can be retained, having supraunitary eigenvalues. The first pattern, corresponding to principal component 1 (PC1), captures the common factors of the Industry 4.0 infrastructure (software and hardware), whereas the second pattern, corresponding to PC2, is called Connectivity and it refers to the ability to create a network of connected devices (Table 2).

Table 2. Factor loadings and contribution of the variables (ADP technologies model)

\begin{tabular}{|l|c|c|c|c|}
\hline Variables & $\begin{array}{c}\text { PC 1. Technological } \\
\text { Infrastructure } \\
\text { (software and } \\
\text { hardware) }\end{array}$ & $\begin{array}{c}\text { PC 2. } \\
\text { Connectivity } \\
\text { (Industrial } \\
\text { Internet of } \\
\text { Tings) }\end{array}$ & $\begin{array}{c}\text { Contribution to } \\
\text { the PC 1 } \\
\text { Variability (\% } \\
\text { from 100\%) }\end{array}$ & $\begin{array}{c}\text { Contribution to } \\
\text { the PC 2 } \\
\text { Variability (\% } \\
\text { from 100\%) }\end{array}$ \\
\hline E_HDI & $\mathbf{0 . 9 0 2}$ & -0.284 & 12.801 & 4.326 \\
\hline E_BD & $\mathbf{0 . 6 2 1}$ & 0.209 & 6.065 & 2.338 \\
\hline E_CC & $\mathbf{0 . 8 6 3}$ & -0.400 & 11.707 & 8.560 \\
\hline E_CC_HI & $\mathbf{0 . 7 9 1}$ & -0.438 & 9.856 & 10.272 \\
\hline E_ERP & $\mathbf{0 . 8 6 6}$ & 0.207 & 11.800 & 2.304 \\
\hline E_CRMAN & $\mathbf{0 . 7 4 3}$ & 0.254 & 8.696 & 3.446 \\
\hline E_P3D & $\mathbf{0 . 9 1 0}$ & 0.110 & 13.038 & 0.647 \\
\hline $\begin{array}{l}\text { E_P3D_PGP } \\
\text { P }\end{array}$ & $\mathbf{0 . 7 5 0}$ & 0.079 & 8.858 & 0.333 \\
\hline E_RBTI & $\mathbf{0 . 8 8 6}$ & -0.117 & 12.345 & 0.728 \\
\hline E_RFID & 0.554 & $\mathbf{0 . 6 9 2}$ & 4.832 & 25.697 \\
\hline E_RFPSDP & 0.012 & $\mathbf{0 . 8 7 8}$ & 0.002 & 41.350 \\
\hline Eigenvalues & 6.355 & 1.865 & & \\
\hline $\begin{array}{l}\text { Variability } \\
\text { (\%) }\end{array}$ & $57.77 \%$ & $16.95 \%$ & & \\
\hline $\begin{array}{l}\text { Cumulative } \\
\text { variability } \%\end{array}$ & $57.77 \%$ & $74.73 \%$ & & \\
\hline
\end{tabular}

Based on the factor loading values and on contributions to the total variability explained by the two patterns (in Table 2), the following stages of technological transition to Industry 4.0 are identified:

$\checkmark$ firstly, companies have to ensure prerequisites for digitization such as high connectivity and access to digital platforms;

$\checkmark$ secondly, companies have to make investments in advanced technological equipment (3D printing and industrial robots), after which an integrated

DOI: 10.24818/18423264/55.2.21.02 
The Technological Transition of European Manufacturing Companies to Industry 4.0. Is the Human Resource Ready for Advanced Digital Technologies? The Case of Romania

production system is achieved, using cloud computing and big data analysis solutions;

$\checkmark$ thirdly, the software and hardware infrastructure created and integrated is tested according to a lower amount of information collected from devices and equipment;

$\checkmark$ the last stage is a major challenge for the company and it refers to increasing connectivity and integration of a large number of devices and equipment to be identified and coordinated in the production process.

Based on the factor scores for each of the 21 countries included in the ADP technologies model, we prepared the chart below, whereby the horizontal axis includes the Technological infrastructure pattern (PC1), and the vertical axis includes the Connectivity pattern (PC2). The positive values of the two factors correspond to a spread of digital technologies above the European average, and the negative values show a technological gap in the manufacturing companies. The countries at the extremities of the two axes contribute the most to the total variance of the estimated patterns. Thus, $29 \%$ of the PC1 variance is due to Finland, while Denmark contributes with $14 \%$, and Romania with $10 \%$. Similarly, Sweden, Austria, Denmark and Germany explain together about 55\% of the PC2 variance.

On the basis of the factor scores and of the two patterns estimated, five groups of countries can be distinguished (Figure 1):

1. Leading countries (ADP model) - Austria, Germany, and Netherlands -, which are characterized by a positive deviation compared to the average in the case of advanced digital technologies (hardware, software, and connectivity). Therefore, the manufacturing companies from these countries make a faster transition towards new technologies, targeting the aspects of smart manufacturing.

2. Countries with Connectivity gap - Finland, Denmark, and Sweden -, which dominate the European innovation and competitiveness rankings, but the connectivity of machines, data, and workers is underdeveloped compared to the technological infrastructure. By boosting the connectivity, the complexity of the integrated production system will significantly increase.

3. Countries with Technological Infrastructure gap - Bulgaria, Slovakia, and Spain -, which have higher progresses in the adoption of the IIoT technology, compared to the investments in other digital technologies, which are more expensive. Consequently, the IIoT potential will increase when big data and cloud computing are adopted on a larger scale, or sensors and RFID tags embedded into industrial robots and 3D printing are used. As the technological gap regarding the infrastructure will decrease, additional investments in connectivity will be necessary.

4. Laggard countries (ADP model) - Romania, Hungary, Cyprus, Czech Republic, Poland, Portugal, and Estonia - which have the lowest spread of

DOI: 10.24818/18423264/55.2.21.02 
technologies for Industry 4.0 in the manufacturing sector. One of the main reasons is the reduced capacity to innovate and to adopt patents in the manufacturing sector, Romania being, for instance, the last one in the EU rankings. These countries are characterized both by technological concentration in a few large companies and by structural problems, such as the absence of financing or of qualified human resources. The technological transition of laggard countries could be performed in a coordinated manner, based on the complementarity between connectivity and the technological infrastructure.

5. Average country group (ADP model) - Malta, France, Lithuania, Slovenia, Italy -, including the economies whose factor scores do not vary by more than $+/-1$ standard deviation point compared to the average of the group, this solution was proposed in the paper (Castelo-Branco, et al., 2019). Still, the level of implementation of technologies is relatively low compared to the countries in the first two groups, suggesting the need to emphasize the transition towards smart manufacturing.

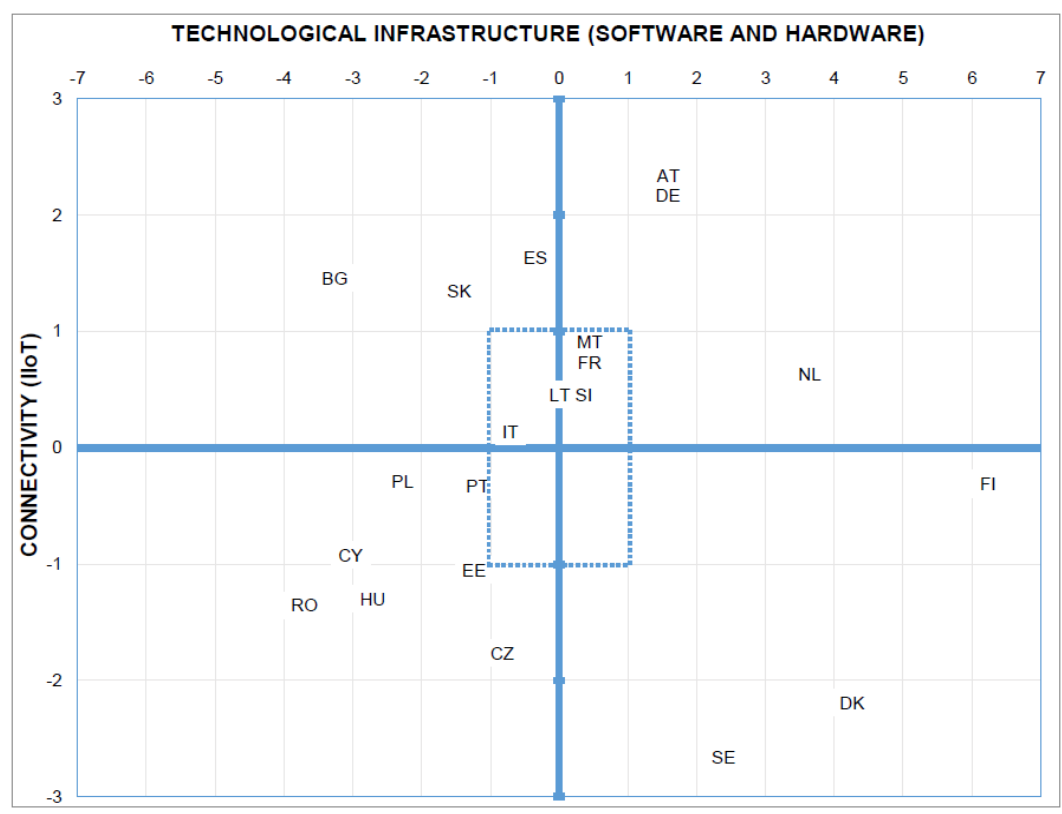

Figure 1. European countries groups according to ADP technologies model

\subsection{Human resource readiness for new advanced digital technologies (Skills and Specializations model)}

The endowment of workers with new skills will allow them to adapt to technological transformations and to work within a cyber-physical system. The new technological challenges require additional skills, even more complex than the ICT 
The Technological Transition of European Manufacturing Companies to Industry 4.0. Is the Human Resource Ready for Advanced Digital Technologies? The Case of Romania

ones, specific to the previous stages of development. Some of these skills are analytical ones, which are necessary to manage a large amount of information, to identify the problems, and to solve them in real time. Other skills relate to communication, adaptability, creativity, or time management, which become essential within the new working environments.

The most important condition of technological progress is workforce development by attracting and preparing workers with complex meta-skills. The perception of specialists in human resources is that digital technological transformations are faster than the capacity of manufacturing companies to find workers with proper skills (Ernst\&Young, 2018). Covid 19 pandemic accelerates digital transformation and emphasizes the need for advanced digital skills. About $90 \%$ of the manufacturing jobs in the EU will require digital skills in the near future, whereas about $60 \%$ of the European manufacturing workers have only basic digital skills (CEDEFOP, 2018). The implementation of advanced technologies in European manufacturing companies will involve advancing the use of technical and operational skills for workers, and a continuous upskilling process, as argued in the report (European Institute for Innovation-Technology, 2020). The increase of the number of ICT and STEM graduates is a prerequisite for improving the skills of the future workforce, according to technological challenges.

To identify patterns of human resource readiness to Industry 4.0 in EU countries, we built a database related to the challenges identified in the literature review. The source of data is the Eurostat database, and the most recent data is from 2019, excepting higher education graduates with the last data from 2018. The model has eight original variables and includes graduates in academic specialization fields in Industry 4.0, digital skills of human resources, and participation in lifelong learning programs by workers from manufacturing companies. The four variables on digital skills are expressed as a percentage of the workforce and the other four have been converted according to the same reference. Unlike the ADP technologies model, data is available for all European Union countries.

Thus, we used ICT graduates of higher education (G_ICT), and science, mathematics, computing, engineering, manufacturing, and construction graduates (G_SMCEMC, as a proxy for STEM graduates), for specialization fields, which are critical enablers of the adoption of Industry 4.0. The current state of the manufacturing sector in terms of advanced skills has been approximated by using the number of workers who are scientists and engineers (SE_M). Furthermore, the propensity for continuous learning of manufacturing workers was analyzed by participation in lifelong learning programs (LLL_M). As the typical worker of Industry 4.0 has both hard and soft digital skills, we used the share of individuals with above basic digital skills. Software skills (SK_S) involve the analysis of data based on software or programming functions, whereas problem-solving skills

DOI: 10.24818/18423264/55.2.21.02 
(SK_PS) aim at the creative use of digital skills to find answers to different challenges within a new working environment. Moreover, individuals have to acquire informational skills (SK_I) and communication skills (SK_C) to adapt to the large amount of data generated in the production process and to the resource sharing process.

The countries are different from the perspective of innovation capacity and flexibility of workers, which will lead to technological gaps widening between them. Among the eight indicators of the model, Romania has above average values only for the number of scientists and engineers in manufacturing, whereas the values of graduates are close to the European average, proving an average potential to adapt human resources to new technologies. The digital skills of Romanian individuals are among the lowest in the EU, which is an obstacle for a rapid spread of new digital technologies across manufacturing companies.

According to the PCA method, we proceeded to calculate the correlation matrix of the original variables used in the Skills and Specializations model, the results being included in Table 3 . The graduates in the two fields of specialization have a relatively high correlation (0.76), due to the positive influence of the technological development on the structure of the higher education system. A statistically insignificant correlation between the G_SMCEMC graduates and workers in manufacturing with such qualifications (G_SMC), shows a low use of those graduates in the manufacturing sector. The four digital skills are significantly positively correlated with the participation of manufacturing workers in training programs, showing that companies are pursuing a strategy of improving skills both for existing and future workers, according to their stage of technological development. The highest correlations are between all four types of digital skills, which suggest their importance to equip individuals and workers with meta-skills.

Table 3. Correlation (Skills and Specializations model)

\begin{tabular}{|l|c|c|c|c|c|c|c|c|}
\hline \multicolumn{1}{|c|}{ Variables } & $\begin{array}{c}\text { G_S } \\
\text { MC } \\
\text { EMC }\end{array}$ & $\begin{array}{c}\text { G__ } \\
\text { ICT }\end{array}$ & SE_M & LLL_M & SK_S & $\begin{array}{c}\text { SK_- } \\
\text { PS }\end{array}$ & $\begin{array}{c}\text { SK_ } \\
\text { I }\end{array}$ & $\begin{array}{c}\text { SK_ } \\
\text { C }\end{array}$ \\
\hline G_SM & & & & & & & & \\
CEMC & $\mathbf{1 . 0 0}$ & $\mathbf{0 . 7 6}$ & 0.34 & 0.23 & 0.21 & 0.16 & 0.15 & -0.11 \\
\hline G_ICT & $\mathbf{0 . 7 6}$ & $\mathbf{1 . 0 0}$ & 0.33 & 0.19 & 0.18 & 0.18 & 0.23 & 0.18 \\
\hline SE_M & 0.34 & 0.33 & $\mathbf{1 . 0 0}$ & $\mathbf{0 . 6 0}$ & 0.37 & $\mathbf{0 . 3 8}$ & 0.34 & 0.23 \\
\hline LLL_M & 0.23 & 0.19 & $\mathbf{0 . 6 0}$ & $\mathbf{1 . 0 0}$ & $\mathbf{0 . 6 5}$ & $\mathbf{0 . 7 3}$ & $\mathbf{0 . 6 0}$ & $\mathbf{0 . 4 5}$ \\
\hline SK_S & 0.21 & 0.18 & 0.37 & $\mathbf{0 . 6 5}$ & $\mathbf{1 . 0 0}$ & $\mathbf{0 . 8 1}$ & $\mathbf{0 . 7 8}$ & $\mathbf{0 . 6 2}$ \\
\hline SK_PS & 0.16 & 0.18 & $\mathbf{0 . 3 8}$ & $\mathbf{0 . 7 3}$ & $\mathbf{0 . 8 1}$ & $\mathbf{1 . 0 0}$ & $\mathbf{0 . 9 0}$ & $\mathbf{0 . 6 9}$ \\
\hline SK_I & 0.15 & 0.23 & 0.34 & $\mathbf{0 . 6 0}$ & $\mathbf{0 . 7 8}$ & $\mathbf{0 . 9 0}$ & $\mathbf{1 . 0 0}$ & $\mathbf{0 . 7 9}$ \\
\hline SK_C & -0.11 & 0.18 & 0.23 & $\mathbf{0 . 4 5}$ & $\mathbf{0 . 6 2}$ & $\mathbf{0 . 6 9}$ & $\mathbf{0 . 7 9}$ & $\mathbf{1 . 0 0}$ \\
\hline
\end{tabular}

Values in bold are different from 0 with a significance level alpha $=0.05$ 
The Technological Transition of European Manufacturing Companies to Industry 4.0. Is the Human Resource Ready for Advanced Digital Technologies? The Case of Romania

We used XL-STAT software and retained only two principal components that have supraunitary eigenvalues, their cumulative contribution being $74.88 \%$ of the overall variability (Table 4). The first pattern (corresponding to the first principal component PC1) was called Skills, as it includes common factors of the original variables related to the digital skills acquired and improved by individuals and workers. The highest contribution to the variability of the Skills pattern comes from problem solving, informational, and software skills. The second pattern (corresponding to the second principal component PC2) was called Specializations, as it includes common factors of higher education graduates in the field of Industry 4.0. The new industrial revolution emphasizes the role of STEM specializations, their contribution to the total variability being $43.2 \%$, which is higher than the contribution of ICT specialization (35.1\%).

Table 4. Factor Loadings and contribution of the variables (Skills and Specializations model)

\begin{tabular}{|l|c|c|c|c|}
\hline \multicolumn{1}{|c|}{ Variables } & PC 1. Skills & $\begin{array}{c}\text { PC 2. } \\
\text { Specializations }\end{array}$ & $\begin{array}{c}\text { Contribution to the } \\
\text { PC1 Variability (\% } \\
\text { from 100\%) }\end{array}$ & $\begin{array}{c}\text { Contribution to the } \\
\text { PC1 Variability } \% \\
\text { from 100\%) }\end{array}$ \\
\hline SE_M & $\mathbf{0 . 5 8 1}$ & 0.351 & 7.989 & 7.018 \\
\hline LLL_M & $\mathbf{0 . 8 0 8}$ & 0.009 & 15.440 & 0.004 \\
\hline SK_S & $\mathbf{0 . 8 6 6}$ & -0.153 & 17.709 & 1.338 \\
\hline SK_PS & $\mathbf{0 . 9 1 9}$ & -0.209 & 19.975 & 2.485 \\
\hline SK_I & $\mathbf{0 . 9 0 4}$ & -0.218 & 19.319 & 2.694 \\
\hline SK_C & $\mathbf{0 . 7 5 2}$ & -0.379 & 13.373 & 8.149 \\
\hline G_SMCEMC & 0.330 & $\mathbf{0 . 8 7 2}$ & 2.580 & 43.199 \\
\hline G_ICT & 0.391 & $\mathbf{0 . 7 8 6}$ & 3.615 & 35.113 \\
\hline Eigenvalues & 4.232 & 1.758 & & \\
\hline Variability & $52.89 \%$ & $21.98 \%$ & & \\
\hline $\begin{array}{l}\text { Cumulative } \\
\text { variability }\end{array}$ & $52.89 \%$ & $74.87 \%$ & & \\
\hline
\end{tabular}

On the basis of the factor scores and of the two patterns estimated, five groups of countries can be distinguished (Figure 2):

1. Leading countries (Skills and Specializations patterns) - Ireland, Finland, Denmark, Austria, France - which have above average values for the two patterns that are going to accelerate the adaptation to new technologies. Education systems, as well as professional training programs and digital skills are enablers for the technological transition of companies, to a greater extent for the first three countries of the group.

2. Countries with specialization gaps - Sweden, Netherlands, Belgium, Luxembourg, Estonia, and Germany -, whose workforce has high digital skills,

DOI: $10.24818 / 18423264 / 55.2 .21 .02$ 
but are faced with a shortage (more acute for the first three countries) of graduates with specialization in the field of Industry 4.0, compared to the technological and digitalization levels of the countries.

3. Countries with skill gaps - Bulgaria, Romania, Poland - which have more specialized graduates and a relatively high potential of technological adoption, but also a human resource with insufficient digital skills (especially for the first two countries). In other words, the human resource is an obstacle for technological transition, but there are expectations that the entry of graduates into the labor market will lead to a boost in technological development.

4. Laggard countries (Skills and Specializations patterns) - Italy, Greece, Cyprus, Latvia, and Portugal -, which are a relatively homogenous group, characterized by a small shortage of specialized graduates and a greater shortage of digital skills. The main challenge of these countries is improving the digital skills and the professional training of workers.

5. Average country group (Skills and Specializations patterns) - Croatia, Slovenia, Malta, Czech Republic, Slovakia, Hungary, Lithuania, Spain -, which includes the countries whose factor scores of both patterns do not vary by more than $+/-1$ standard deviation point compared to the average of the group, the last four ones being closer to the countries in the previous cluster.

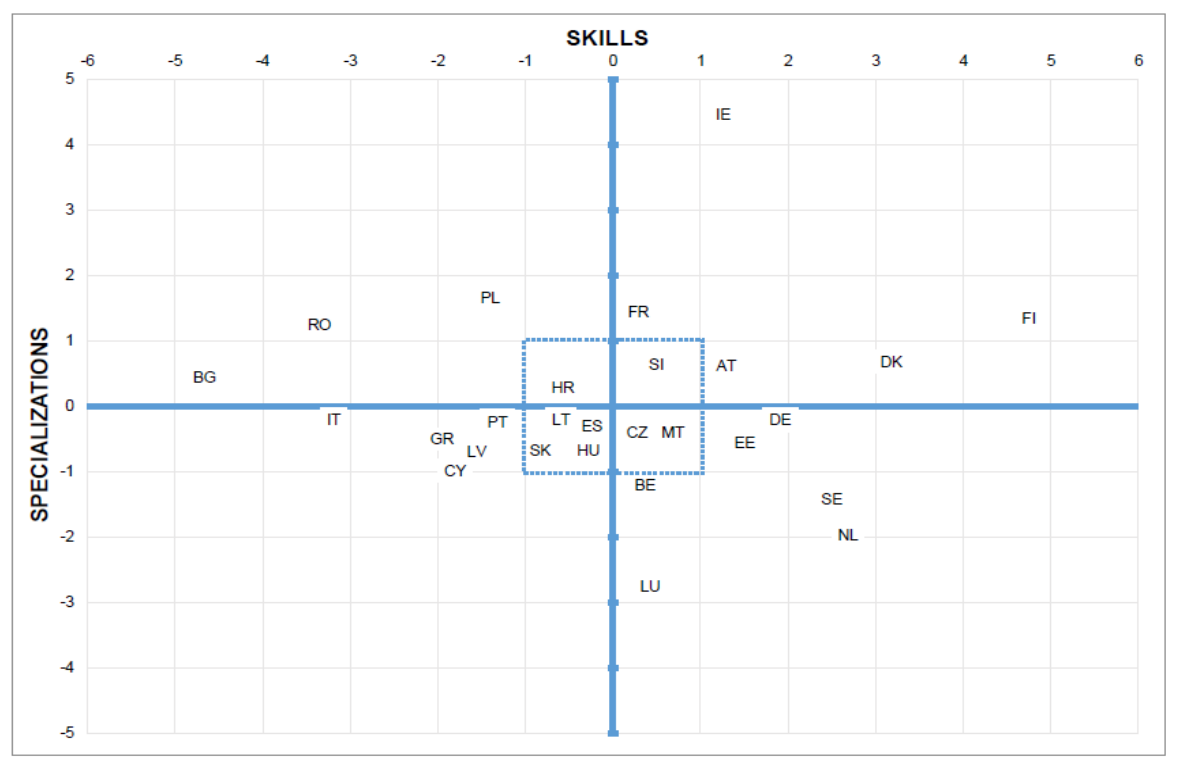

Figure 2. European countries groups according to Skills and Specializations model 
The Technological Transition of European Manufacturing Companies to Industry 4.0. Is the Human Resource Ready for Advanced Digital Technologies? The Case of Romania

\subsection{Grouping the EU countries according to estimated patterns}

The developed EU economies are characterized by a virtuous relationship between the ability to innovate and implement new technologies, on the one hand, and the ability of the human resource to adapt to technological change, on the other hand. Moreover, these countries developed strong partnerships between universities, R\&D projects, and business companies. Even if some of them have been ranked among the countries with a gap in adopting IIoT or in specialized graduates (Table 5), the countries do not necessarily have structural weaknesses. On the contrary, it may be a prioritization of investment in the hardware and software of manufacturing companies, or in improving digital skills for most individuals and workers. The less developed European countries seem to adapt more slowly to digital and technological changes, due both to the slower spread of technology in the manufacturing sector and to the shortage of digital skills for workers. The specialization fields in the tertiary education systems of most CEE countries are still influenced by their economic development stage in which the manufacturing sector has a higher contribution to the gross value added. Therefore, these countries are going to have more specialized graduates, but their potential should be harnessed by the domestic manufacturing sector and not wasted through emigration.

Table 5. EU country classification

\begin{tabular}{|c|c|c|c|c|c|}
\hline & $\begin{array}{l}\text { Leading } \\
\text { (ADP) }\end{array}$ & $\begin{array}{l}\text { Connectivity } \\
\text { (IIoT) gap }\end{array}$ & $\begin{array}{l}\text { Infrastructure } \\
\text { gap }\end{array}$ & $\begin{array}{c}\text { Laggard } \\
\text { (ADP) }\end{array}$ & $\begin{array}{l}\text { Average } \\
\text { group } \\
\text { (ADP) }\end{array}$ \\
\hline $\begin{array}{l}\text { Leading (skills and } \\
\text { specializations) }\end{array}$ & AT & FI, DK & \multirow[b]{2}{*}{ - } & - & FR \\
\hline Specializations gap & $\mathrm{DE}$ & SE & & EE & \\
\hline Skills gap & \multirow[t]{3}{*}{ NL } & & BG & RO, PL & - \\
\hline $\begin{array}{l}\text { Laggard (skills and } \\
\text { specializations) }\end{array}$ & & & SK & $\mathrm{CY}, \mathrm{PT}$ & IT \\
\hline $\begin{array}{l}\text { Average group (skills } \\
\text { and specializations) }\end{array}$ & & & ES & $\mathrm{CZ}, \mathrm{HU}$ & $\begin{array}{l}\text { SI, LT, } \\
\text { MT }\end{array}$ \\
\hline
\end{tabular}

\section{Conclusions}

Based on the results obtained in this study, we claim that the technological transition of the manufacturing sector to Industry 4.0 will not occur homogenously, either at the level of the EU member states, or domestically, at the level of each individual country. Usually, the most powerful companies of the developed economies have a greater capacity to innovate and to invest in advanced digital technologies. In addition, companies buy the newest technological innovations or software and attract the most highly qualified graduates and workers. Instead, companies from less developed economies will continue to have a low level of

DOI: 10.24818/18423264/55.2.21.02 
technology. Similarly, the workforce with advanced digital skills will continue to prefer developed countries and large companies, as they offer higher wages. Consequently, the capital, the workforce, as well as the technologies for Industry 4.0 will be located in developed countries and in powerful companies. Central and East European and South East countries will, at best, have only a few technological enclaves within the manufacturing sector where the majority of companies are in the previous stages of the industrial revolution. The presence of advanced technological enclaves is always a more favorable situation than their absence, but such companies must be encouraged to create digital clusters and to engage in digital responsibility programs for individuals.

From a theoretical point of view, the European countries with a larger percentage of students, graduates, and workers endowed with hard and digital skills will have a higher potential to adopt new technologies in the manufacturing sector. The Romanian reality, similar to that found in other less developed countries, contradicts this theoretical view due to at least three reasons. The first refers to the lower capacity of manufacturing companies to innovate, to attract talents resulting from the higher education system and to harness their potential (Bălăceanu et al., 2020). The second relates to the use of highly skilled workers in the companies from the technological enclaves mentioned above. If the workforce with lower digital skill levels does not quickly adjust to the new requirements, then the positive spillover of technological enclaves will not occur. The third reason is the consequence of the previous two and refers to the most pressing problem of certain CEE countries. It involves the brain drain phenomenon, which creates a significant shortage of specialized individuals for new technologies in less developed countries.

Romania is already in a vicious circle generated both by the technological level and by the quality of the human resource, which has amplified due to the transition to Industry 4.0. On the one hand, the higher educated and qualified workforce emigrates in the absence of a stronger innovation system, and due to poor opportunities to harness advanced skills domestically. On the other hand, progress towards digitalization is limited by the high shortage of qualified workforce. Industry 4.0 enhances the risk of brain drain, without implying an actual physical movement of the workers to the developed countries, which have a natural ability to attract them.

The results of the study lead to a pessimistic view of the capacity of Romania to achieve quick progress and to reduce the technological gap. However, there are smart measures to skip the stages of the technological transition, as we proposed in the case of Romania:

$\checkmark$ Adopting as quickly as possible a digitalization strategy for the manufacturing sector, which should include European best practices and technological guidelines for the transition of manufacturing companies. The main goal should be to harness digital development opportunities to make an easier transition to more complex technologies.

DOI: $10.24818 / 18423264 / 55.2 .21 .02$ 
The Technological Transition of European Manufacturing Companies to Industry 4.0. Is the Human Resource Ready for Advanced Digital Technologies? The Case of Romania

$\checkmark$ Integrating researchers and companies from Romania in European research teams connected to smart manufacturing technologies.

$\checkmark$ Creating digital platforms that will integrate most of the domestic innovative solutions for the implementation of manufacturing advanced technologies.

$\checkmark$ Granting state aids and fiscal facilities (exemption from profit tax) to manufacturing companies investing in new technologies, especially in advanced industrial robots. The most significant facilities will be granted for investment in greenfield smart factories.

$\checkmark$ Enforcing the fiscal deductibility of the expenditure incurred for the improvement of the advanced digital skills of workers.

$\checkmark$ Expanding technological hubs with higher involvement of students, graduates, and companies in the digital field.

$\checkmark$ Organizing job fairs for Industry 4.0, including for graduates in specialization fields for new technologies.

$\checkmark$ Changing the curriculum to ensure more complex digital skills to pupils and students, by establishing mandatory robotics courses, inter alia.

$\checkmark$ Implementing the Corporate digital responsibility concept (new in the literature) in the governance system of digital and technological companies and encouraging cultural digitization projects (Fanea-Ivanovici and Pană, 2020), also within poorer communities.

\section{REFERENCES}

[1] Andreoni, A., Anzolin, G. (2019), A Revolution in the Making? Challenges and Opportunities of Digital Production Technologies for Developing Countries. Inclusive and Sustainable Industrial Development Working Paper Series, no. 7, Vienna;

[2] Bajenaru, L., Smeureanu, I., Balog, A. (2016), An Ontology-based Elearning Framework for Healthcare Human Resource Management. Studies in Informatics and Control, vol. 25, Issue 1;

[3] Bălăceanu, C., Gruiescu, M., Coculescu, C., Iacob, O. (2020), The Romanian Educational System. A Critical Analysis. Economic Computation and Economic Cybernetics Studies and Research, Issue 1, pp. 215-232;

[4] Boston Consulting Group (2019), Putting Industry 4.0 to Work. [Online]. Available: https://www.bcg.com/capabilities/manufacturing/industry-4.0;

[5] Calza, E., Fokeer, S. (2019), Absorbing Advanced Digital Production Technologies to Foster Industrialization. Evidence from Case Studies in Developing Countries. Inclusive and Sustainable Industrial Development Working Paper Series, no. 9, Vienna;

DOI: $10.24818 / 18423264 / 55.2 .21 .02$ 
Marius Marinas, Marin Dinu, Aura Gabriela Socol, Cristian Socol

[6] Castelo-Branco, I., Cruz-Jesus, F., Oliveira T. (2019), Assessing Industry 4.0 Readiness in Manufacturing: Evidence for the European Union, Computers in Industry, vol. 107, pp. 22-32;

[7] CEDEFOP (2018), Insights into Skill Shortages and Skill Mismatch: Learning from Cedefop's European Skills and Jobs Survey. Brussels, [Online]. Available: https://www.cedefop.europa.eu/en/publications-andresources/publications/3075;

[8] Culot, G., Nassimbeni, G., Orzes, G., Sartor, M. (2020), Behind the Definition of Industry 4.0: Analysis and Open Questions. International Journal of Production Economics, vol. 15, pp. 1-47;

[9] Ernst \&Young (2018), Building a Better Working Europe Unlocking Europe's Digital Growth Potential. EY's Attractiveness Survey, [Online]. Available: https://assets.ey.com/content/dam/ey-sites/eycom/en_gl/topics/attractiveness/ey-european-attractiveness-survey-building-abetter-working-europe.pdf;

[10] European Institute for Innovation - Technology (2020), Skills Data Collection for Connectivity Devices and Services/CDS (IOT in Smart Manufacturing). Slovenia [Online]. Available: https://talentjourney.si/wpcontent/uploads/2020/09/1_Skills-Data-Collectiom_Talentjourney-Report-2.1Final.pdf;

[11] Eurostat (2020), Methodological Manual for Statistics on the Information Society. ICT Usage and e-commerce in Enterprises Survey Year 2020. Version 1.3. [Online]. Available: https://circabc.europa.eu/faces/jsp/extension/wai/navigation/container.jsp;

[12] Fanea-Ivanovici, M., Pană, M. (2020), From Culture to Smart Culture. How Digital Transformations Enhance Citizens' Well-Being through Better Cultural Accessibility and Inclusion. in IEEE Access, vol. 8, pp. 37988-38000;

[13] Glawe, L., Wagner, H. (2020), The Middle-Income Trap 2.0: The Increasing Role of Human Capital in the Age of Automation and Implications for Developing Asia. Asian Economic Papers, vol. 19, no.3, pp. 40-58;

[14] Greer, C., Burns, M., Wollman, D., Griffor, E. (2019), Cyber-Physical Systems and Internet of Things. NIST Special Publication, vol. 1900-202, pp. $1-61$;

[15] Hair, J.F., Black, W.C., Babin, B.J., Anderson, R.E. (2019), Multivariate Data Analysis. Boston, Massachusetts: Cengage Learning, 2019;

[16] Leitão, P., Pires, F., Karnouskos, S., Colombo, A.W. (2020), Quo Vadis Industry 4.0? Position, Trends, and Challenges. IEEE Open Journal of the Industrial Electronics Society, vol. 1, pp. 298-310;

[17] Luthra, S., Mangla, S.K. (2018), Evaluating Challenges to Industry 4.0 Initiatives for Supply Chain Sustainability in Emerging Economies. Process Safety and Environmental Protection, vol. 117, pp. 168-179; 
The Technological Transition of European Manufacturing Companies to Industry 4.0. Is the Human Resource Ready for Advanced Digital Technologies? The Case of Romania

[18] Morandini, M.C., Thysen, A.T., Vandeplas, A. (2020), Facing the Digital Transformation: Are Digital Skills Enough? European Economy - Economic Briefs, no 54, pp 1-26;

[19] Naudé, W. (2017), Entrepreneurship, Education and the Fourth Industrial Revolution in Africa. IZA Discussion Paper, no. 10855, pp. 1-25;

[20] Smeureanu, I., Bassel, D.B. (2020), Investigating Top Management Preparedness for Leading IT Governance during the Coronavirus Crisis. Economics\&Sociology, vol 13, Issue 4, pp 97-106;

[21] Thames, L., Schaefer, D. (2017), Industry 4.0: An Overview of Key Benefits, Technologies, and Challenges in Cybersecurity for Industry 4.0, Springer, pp. 1-33;

[22] UNIDO (2020), Industrial Development Report 2020. Brief No 1, [Online]. Available: https://www.unido.org/sites/default/files/files/202004/IDR2020_Brief\%201_final_0.pdf;

[23] Yao, X., Zhou, J., Zhang, J., Boër, C.R. (2017), From Intelligent Manufacturing to Smart Manufacturing for Industry 4.0 Driven by Next Generation Artificial Intelligence and Further on. 2017 5th International Conference on Enterprise Systems (ES), Beijing, pp. 311-318;

[24] Yong, A.G., Pearce, S. (2013), A Beginners Guide to Factor Analysis: Focusing on Exploratory Factor Analysis. Tutorials in Quantitative Methods for Psychology, vol. 9, no. 2, pp. 79-94;

[25] Zheng, P., Wang, H., Sang, Z., Zhong, R.Y., Liu, Y., Liu, C et al. (2018), Smart Manufacturing Systems for Industry 4.0: Conceptual Framework, Scenarios, and Future Perspectives. Frontiers of Mechanical Engineering, vol. 13, no.2, pp.137-150.

DOI: $10.24818 / 18423264 / 55.2 .21 .02$ 